\title{
Stress Analysis of Friction Stir Spot Welded Magnesium Alloy Sheet under Tensile-Shear Load
}

\author{
Ahmet Atak \\ Department of Industrial Design, Faculty of Architecture, Gazi University, Turkey \\ Received September 10, 2019; Revised October 17, 2019; Accepted October 26,2019
}

Copyright $\bigcirc 2019$ by authors, all rights reserved. Authors agree that this article remains permanently open access under the terms of the Creative Commons Attribution License 4.0 International License

\begin{abstract}
The strength, failure location and modes of AZ31B Magnesium sheets with $1.5 \mathrm{~mm}$ thickness, joined using friction stir spot welding (FSSW), can be determined using tension-shear tests. However, the joined materials have different tension test and elastic-plastic characteristics. Elastic analysis methods for spot welding have been examined in detail in literature. However, if the material has narrow elastic and large plastic area characteristics, such as AZ31B, elastic-elastic analysis methods are deficient. The development and application of elastic-plastic analysis methods are required for such soft metal materials. In this study, the elastic-elastic and elastic-plastic analytical stress mechanisms were investigated. Strain and force equations were then derived using an analytical approach. These developed equations were based on the FSSW-Tension-Shear-Test and verified using Finite Element Method (FEM)-Analysis and tension-shear tests. In addition, the location of failure was also determined. It is possible to predict failures without performing tension-shear tests using the proposed analytical equations.
\end{abstract}

Keywords Elastic-plastic Analysis, Failure Mode Analysis, Friction Stir Spot Welding

\section{Introduction}

Numerous studies have investigated the stress mechanisms of joints made using overlapped Resistance Spot Welding (RSW) [1]. Although resistance spot welding is generally used when welding automotive steels, it can also be employed when fabricating Aluminum (Al) alloy and Magnesium (Mg) alloy components. However, dissimilar $\mathrm{Al}$ alloy/steel joining using RSW is problematic due to the widely differing base material properties. FSSW is the natural alternative to resistance spot welding, and produces joints, which have acceptable mechanical properties when joining steel, $\mathrm{Al}$ alloy and $\mathrm{Mg}$ alloy sections [2]. Using the design principle shown in Figure 1, which is commonly used for the simplest sizing, spot-welding design can be generated as given by equation (1)[1] based on the mean shear stress $\left(\tau_{x}\right)[3]$.

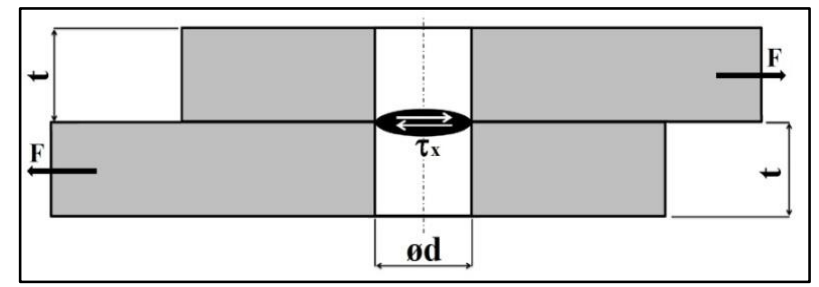

Figure 1. Stress mechanism based on shear stress used commonly for spot-welding design (F:Tension-shear force; t:thickness; ød: diameter of spot weld; $\tau_{x}$ : Shear stress)

A few earlier research reported on the stress mechanisms at the overlapped joints [2-12]. Shen Z. have been investigated AA7075-T6 Aluminum sheet with a mean yield value of $500 \mathrm{MPa}$ and the intended result was achieved only for elastic-elastic analysis. Given that 7000-Series Aluminum is a fragile hard material having a high strength, rupture failures occur without being subject to plastic deformations. The failure types have also been demonstrated only for elastic-elastic analysis [3]. Therefore, in the present study were considered elastic-plastic analysis of the joining to build a model for a ductile material that used in light metal designs as here with AZ31B.

Bozkurt Y. et al. have compared the rupture strength and shear-tensile forces of overlapped joints of AA2024 Aluminum alloy sheet material using FSSW and RSW methods only [4]. AA2024 is a ductile material that a bit stronger than AZ31B. AA2024 is less ductile and has more strength compared to AZ31B. But no information was provided on the stress mechanism at the presented overlapped joints, which were needed in this study to build a good correlated model with tensile-shear test results.

Akdoğan A. has investigated aluminum and magnesium 
alloy mechanical properties by considering their strengths and weights in her study. Tablel shows tensile test results of 7000 series $\mathrm{Al}$ and AZ31B magnesium alloys. AZ31B test result in Table 1 has been achieved with tensile test in this study and details will be given in the following section 2.1. As seen from Table 1, 7000 series $\mathrm{Al}$ alloys elongation is around $15 \%$, while AZ31B magnesium alloy elongation is around $21 \%$. It shows clearly that AZ31B is more ductile than 7000 series aluminum alloys. Additionally, 7000 series Al has higher strength than AZ31B [5].

Table 1. Tensile test results of AZ31B and 7000 series $\mathrm{Al}$ alloys.

\begin{tabular}{|c|c|c|c|c|}
\hline \multirow{2}{*}{ Material } & $\begin{array}{c}\text { Elastic } \\
\text { modulus }\end{array}$ & $\begin{array}{c}\text { Yield } \\
\text { strength }\end{array}$ & $\begin{array}{c}\text { Tensile } \\
\text { strength }\end{array}$ & Elongation \\
\cline { 2 - 5 } & $\mathrm{E}(\mathrm{GPa})$ & $(\mathrm{MPa})$ & $(\mathrm{MPa})$ & $(\%)$ \\
\hline AZ31B & 45 & 151 & 253 & 21.4 \\
\hline $7004-\mathrm{T} 5$ & 72 & 340 & 400 & 15 \\
\hline 7005-T53 & 72 & 350 & 395 & 15 \\
\hline $7116-\mathrm{T} 5$ & 70 & 315 & 360 & 14 \\
\hline $7029-\mathrm{T} 5$ & 70 & 380 & 430 & 15 \\
\hline $7129-\mathrm{T} 5$ & 70 & 380 & 430 & 15 \\
\hline
\end{tabular}

Kim J. et al. have investigated the fabrication of screw joints using various FEM-Modelling techniques and numerical and empirical determination of stiffness values [6]. The materials used had very high strength values and were used to compare different FEM-modelling techniques only. But, the FEM-Modelling techniques were used in the current study.

Serindag H.T. et al. have done a numerical and experimental study on friction stir welding of AZ31 magnesium alloys. In the finite element analyses, modeling of the FSW process were carried out by ANSYS software to determine the stress distributions in the welded joint during FSW. Transient nonlinear finite element analyses were performed to make structural stress analysis. It has seen that the welding performance increases as both low transverse speed and high rotational speed increase [7]. In that study, nonlinear ultimate stress analysis has been performed with nonlinear material information. Only calculated tension force was applied to the sample and stress values are achieved.

Reynolds A.P. et al. investigated structure, properties, and residual stress of 304L stainless steel friction stir welds in their studies. They showed that the sign of the transverse residual stress changes from tensile at the crown to compressive at the root, producing a bending moment about the longitudinal axis and hence, plate distortion [8]. In this study, residual stresses are not considered because of the low level stresses in accordance with to yield stress values.
Yuan W. investigated the effect of tool designs and process parameters on aluminum alloys microstructure and mechanical properties of friction stir spot welds in his thesis. The properties of friction stir spot welds vary greatly depending on tool design, welding process parameters, and material needs to be welded. Friction stir spot welding (FSSW) of 6016-T4 aluminum alloy sheet was evaluated. Tool rotation speed, plunge depth, plunge speed and dwell time were varied to determine the effect of individual process parameter on lap-shear failure load. Results indicated that tool rotation speed and plunge depth profoundly influenced lap-shear failure load of welds, while plunge speed and dwell time had little effect [9]. In the present study, rotation speed, plunge depth, plunge speed and dwell time processing parameters are selected constantly.

Li Y. et al. have summarized the joining of magnesium alloy materials using the FSW-Method and proposed an elastic-plastic non-linear empirical material model for magnesium based on micro particle diameter and stiffness [10]. This study was utilized for elastic-plastic material modeling for tensile stress-strain mechanism and developed an empirical equation based on micro structural grain size for not overlapped joining. Li Y.'s report helped to understand, that the strength mechanism of the joining of AZ31B were deformed not only elastic but also plastic. In this study, it has to be investigated that the stress mechanism of overlapped joining in macro structural view, because it is not needed any grain size and complicated studying of microstructure.

Lai W.-J. et al. examined failure modes and fatigue strengths of Magnesium and Steel material joined using ultrasonic spot-welding [11]. They have investigated joining two different materials and their failure mechanisms. These section on failure modes was studied to understand the investigated overlapped joint in the present study.

Parra B. et al. examined the joining of AA6181-T4 Aluminum alloy sheets using FSSW and the failure modes (Figure 2) in tension-shear tests [12]. These section on failure modes was investigated to reviewing of overlapped joint in current study. Although all the failure modes shown herein might occur, (c)-type failure was observed more often when joining was well performed. The reason of this, weak upper plate occurs because of keyhole and secondary moments arised during welding. Theoritically explanations of this phenomenon will be given in 2.2.1 and 2.2.2 sections of this study. (See 6-7 and 12-16 equations) 


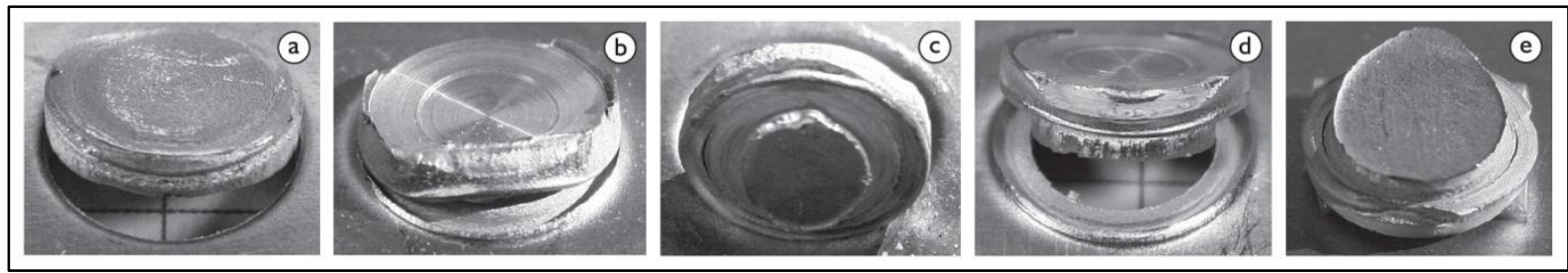

Figure 2. Failure modes seen in Tension-shear test are as follows: a) Failure from welding circumferentially, b) Tear by pulling out from nugget, c) Failure by pulling out from upper sheet, d) Failure by pulling out from the lower sheet, e) Failure from all pieces [7]

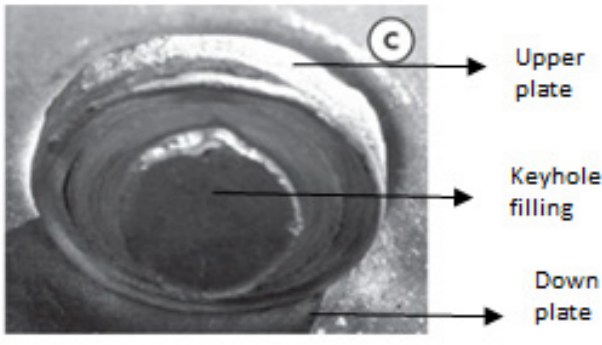

Figure 3. Detailed representation of the $\mathrm{c}$ type failure

Ibrahim I.J. et al, showed the keyhole effect on the weld stress mechanism in their studies. The keyhole, which inevitably remains at the center of the weld after retraction of the FSSW tool, is considered as a critical issue that causes stress concentration and a decrease in the active welding area of the spot weld. They emphasized importance of refilling strategies and approaches on removing the keyhole defect in their studies. Intermediate layer friction stir spot welding (IL-FSSW) is introduced in this study as a novel spot welding technique to eliminate the keyhole associated with the conventional friction stir spot welding (FSSW). This process is utilized for fabricating a joint of 6061-T6 and 2024-T3 aluminum alloys [13].

Yang X.W.et al. showed clearly that there are still important issues that need to be revealed for FSSW processing. FSSW techniques without keyhole defect should be paid more attention. The materials used in FSSW should be enlarged. Besides aluminum and magnesium alloys, engineering plastics and other materials also need to be introduced into the research scope. The flexible multipurpose, and reliable FSSW equipment should be developed for better applications in industrial production [14].

The diameters based on the smallest thickness shown in Table 2 for the spot-welding diameter design are given in Roloff - Matek Maschinenelemente (Machine Elements) book [1].

Table 2. Recommended spot-welding diameter (ød) values based on sheet thickness (t) [Roloff-Matek]

\begin{tabular}{|c|c|c|c|c|c|}
\hline Smallest sheet thickness t [mm] & 1.5 & 2 & 3 & 4 & 5 \\
\hline Spot diameter ød [mm] & 5 & 6 & 8 & 10 & 12 \\
\hline
\end{tabular}

It was concluded in this book that stresses were created based on elastic-elastic analysis, which is valid for materials with high strength but not for the materials used in this study. The equation $8 \mathrm{~mm} \geq d=\sqrt{25 \mathrm{~mm} \cdot t_{\min }[\mathrm{mm}]}$ was given for the spot-welding diameter ød [15].

Chao Y. J. showed the boundary stress and failure mechanism, as well as the mean elastic stress equations [16-17]. These equations were used in capital 2.2.1 in the study and helpful to understand firstly the elastic-elastic stress mechanism that good correlated with high stress materials. However, they are not suitable for the elastic-plastic analysis required for ductile materials.

Radakovic D. J. et al. worked on the predictability of tension-shear strength for steels with high strength using a notch mechanics method [18]. Although the study was very successful, its contribution to this current study is limited due to the different method utilized and the high steel strength of the materials used.

Campanelli L.C. et al. has studied on microstructural features and mechanical performance under shear loading along the cross-section of AZ31 magnesium alloy friction spot welded joints made using different combinations of welding parameters. Static lap shear testing was performed to evaluate the mechanical properties of the welded joints, and the resulting fracture mechanisms and crack propagation paths were fully examined. He showed different fracture modes under shear loading. He investigated plastic flow in the regions subjected to high tensile stresses near the interface between the overlapped sheets, and cracks tend to propagate according to stress distribution. Fracture modes were determined by the magnitude of hook vertical displacement as well as the effect of the superior bonding line and the flexural operating loading [19]. In this study, high tensile stresses near the interface between the overlapped sheets is investigated by considering plastic region deformations.

Campanelli L.C et al. has modeled a FSSW joint on AZ31 magnesium alloy sheets and subsequently submit the assembly to a typical shear test loading in a separate study. They used a linear elastic model, in order to conceive mechanical tests results. Finite element analysis showed that the plastic flow is concentrated on the welded zone periphery where yield strength is reached. It is supposed that "through the weld" and "circumferential pull-out" variants should be the main failure behaviors, although mechanical testing may provide other types of fracture due to metallurgical features. [20]. They defined sheets as 
isotropic linear elastic material in FEM. In the current study material is defined as non-linear by means of stress-strain curve moments on the structure. It shows clearly that elastic and plastic analyses should be applied at which conditions. The standard supports the plastic analysis approximation idea which has been given in that code. Basically, standard says that non-linear plastic analysis can be done by considering the partial plastification of members in plastic zones. Additionally, plastic global analysis may be used where the members are capable of sufficient bending capacity to enable the required redistributions of bending moments. This specification has been used in current study to derivate the formulas depending on static balance requirements. It shows bi-linear stress-strain relationship curve to perform plastic analysis. Same curve which has been obtained from test and applied to the FEM as material input in this study. Eourocode 3 standard classify the cross sections to identify resistance and rotation capacity limits because of local buckling of the joint. It means that joint should be bended under plastic load without catasthrophic failure in the system. Bending on the joint under tension load produce moment effect but moment is limited by means of local buckling. In that study, plastic loads are calculated by considering static balance requirements for forces and moments [21].

Below two conditions should be satisfied in according to "Eurocode 3 in Beispielen" document to determine plastic load value for such a system which statically and kinematically balanced;

1. Static system allowable stress level should provide static balance,

2. Kinematic system allowable shear level should not prevent static balance.

These two conditions can be shown as below equality:

$$
F_{\text {plastic load }}=F_{\text {limit load }}
$$

In case kinematic force is higher than limit force value, structural system will collapse. In case of zero or too low shear availability, system will be too rigid and over safe. To provide safe and optimized structures, systems should be evaluated under their specified plastic loads. This theory totally supports the presented study plastic load usage strategy during design of structures [22].

Based on a thorough review, it was determined that elastic-plastic or full-plastic analysis has not been performed for overlapped joints made using the spot-welding method. There wasn't found any investigation in the studied area for elastic-plastic or full-plastic analysis regarding overlapped joining of ductile material characteristic that examined in this study.

Design method based only on shear stress is suitable for materials with high tensile strength that demonstrate elastic-elastic behavior. These materials exhibit rupture failure due to shear stress without being subject to plastic deformation. However, since soft materials such as AZ31B
Magnesium alloy or EN AW 2024 Aluminum alloy in light metal alloys, as in this study, demonstrate a very narrow elastic and very large plastic area (Figure 2) with a strain up to $20 \%$, an elastic-plastic or even full-plastic stress analysis mechanism should be considered.

In this study, the mechanical characteristics of AZ31B Magnesium alloy material were determined by initially performing a tension test on the main material. A mathematical material model was then established for the FEM. The strain mechanisms in the overlapped FSSW tension-shear sample were analytically examined for elastic-elastic and elastic-plastic analysis methods. Furthermore, the analytical approach was evaluated by performing an analysis using the FEM and the accuracy of the analytical approach was verified based on the results of the tension-shear tests performed. Performed studies have been summarized as below flow chart through in this study (Chart 1) and results were achieved for plastic region.

EN 1993-1-1 (2005) Eurocode 3 standard gives the detailed information about method of finite element analysis considering material non-linearities to get internal forces and

Chart 1. Flow chart of study.

AZ31B Magnesium alloy material tension test has been performed.

Tensile and yield stress values are measured. Failed weld regions are detected.

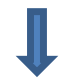

Tensile forces are derived and calculated for elastic-elastic and elastic-plastic stress mechanism by using measured yield stress values on the joint interfaces for $\mathrm{x}$ and $\mathrm{y}$ directions. Critical failed weld point is selected same with the failed region during test

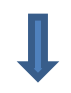

Nonlinear FEM simulations have been done by using calculated tensile forces. Higher stress values on the weld region are compared with the region which is failed during tensile test.

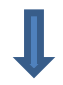

FEM stress results and failed weld regions are compared with test data.

\section{Analytical and Experimental Details}

\subsection{Material Characteristics of AZ31B Main Material Tension-Shear Test Sample and Empirical Material Modelling}

The mechanical characteristics of the main material were determined using tension tests in accordance with ISO 6892-1 and the INSTRON 3369 machine. Test machine and the sample sizes used in the tension test are shown in Figure 4 and Figure 5. 


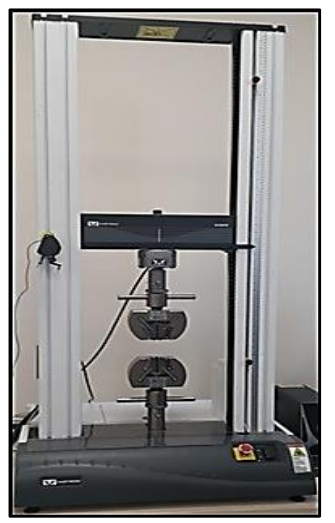

Figure 4. INSTRON 3369 Tension test machine

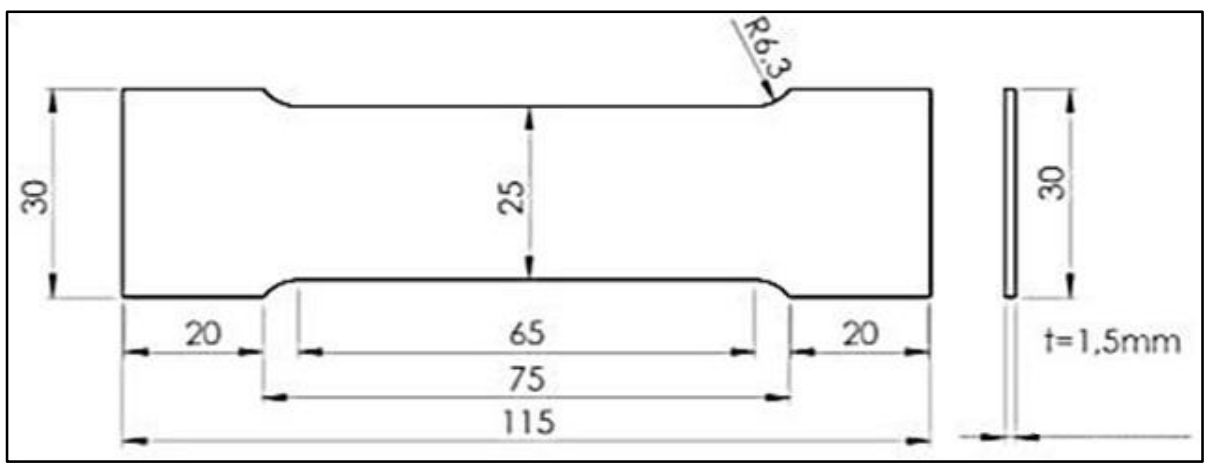

Figure 5. Tension test sample sizes in accordance with ISO 6892-1

The chemical and mechanical characteristics of the AZ31B material are given in Table 3 and Table 4 in accordance with the standards. Selected AZ31B test material is rolled and sample tensile direction is same with the rolling direction of material.

Table 3. Chemical characteristics of Magnesium alloy AZ31B (ASTM, 2010)

\begin{tabular}{|c|c|c|c|c|c|c|c|c|c|}
\hline Alloy & $\mathrm{Al}$ & $\mathrm{Ca}$ & $\mathrm{Cu}$ & $\mathrm{Fe}$ & $\mathrm{Mn}$ & $\mathrm{Ni}$ & $\mathrm{Si}$ & $\mathrm{Zi}$ & $\mathrm{Mg}$ \\
\hline$\%$ & $2.5-3.5$ & 0.04 & 0.05 & 0.005 & $0.2-1.0$ & 0.005 & 0.1 & $0.6-1.4$ & Remai-ning \\
\hline
\end{tabular}

Table 4. Mechanical characteristics of Magnesium alloy AZ31B (ASTM, 2010)

\begin{tabular}{|c|c|c|c|}
\hline Temper & Tensile Stress (MPa) & Yield Stress (MPa) & Elongation (\%) \\
\hline T4 & 240 & 145 & $\geq 7$ \\
\hline
\end{tabular}

Tension test results for the magnesium alloy sheets are shown in Figure 6. Among the four samples prepared for tests as (a), (b), (c) and (d), acceptable results were obtained from (c) and (d) only.

Standard test samples (AZ31B) welded with stir tool shoulder profile shown in Figure 5 were exposed to tensile-shear tests. 5 axis milling machine has been used during FSSW process.

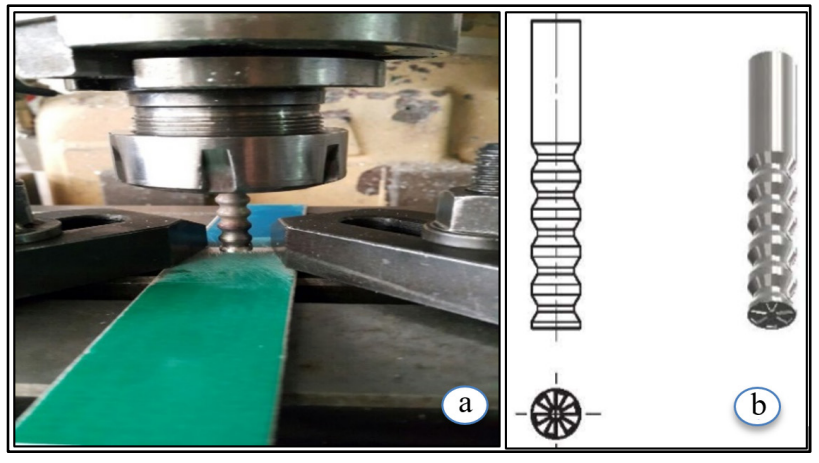

Figure 6. a) FSWW equipment with stir tool and fixing bolts; b) FSWW equipment stir tool design. 
According to the main material tests performed with magnesium alloy sheets with $1.5 \mathrm{~mm}$ thickness in accordance with the standards, the non-linear Stress-Strain function data presented in Figure 6 was used in FEM modelling and in FEM-Analysis as a table based on the fourth-degree polynomial interpolation equation given in Figure 7.

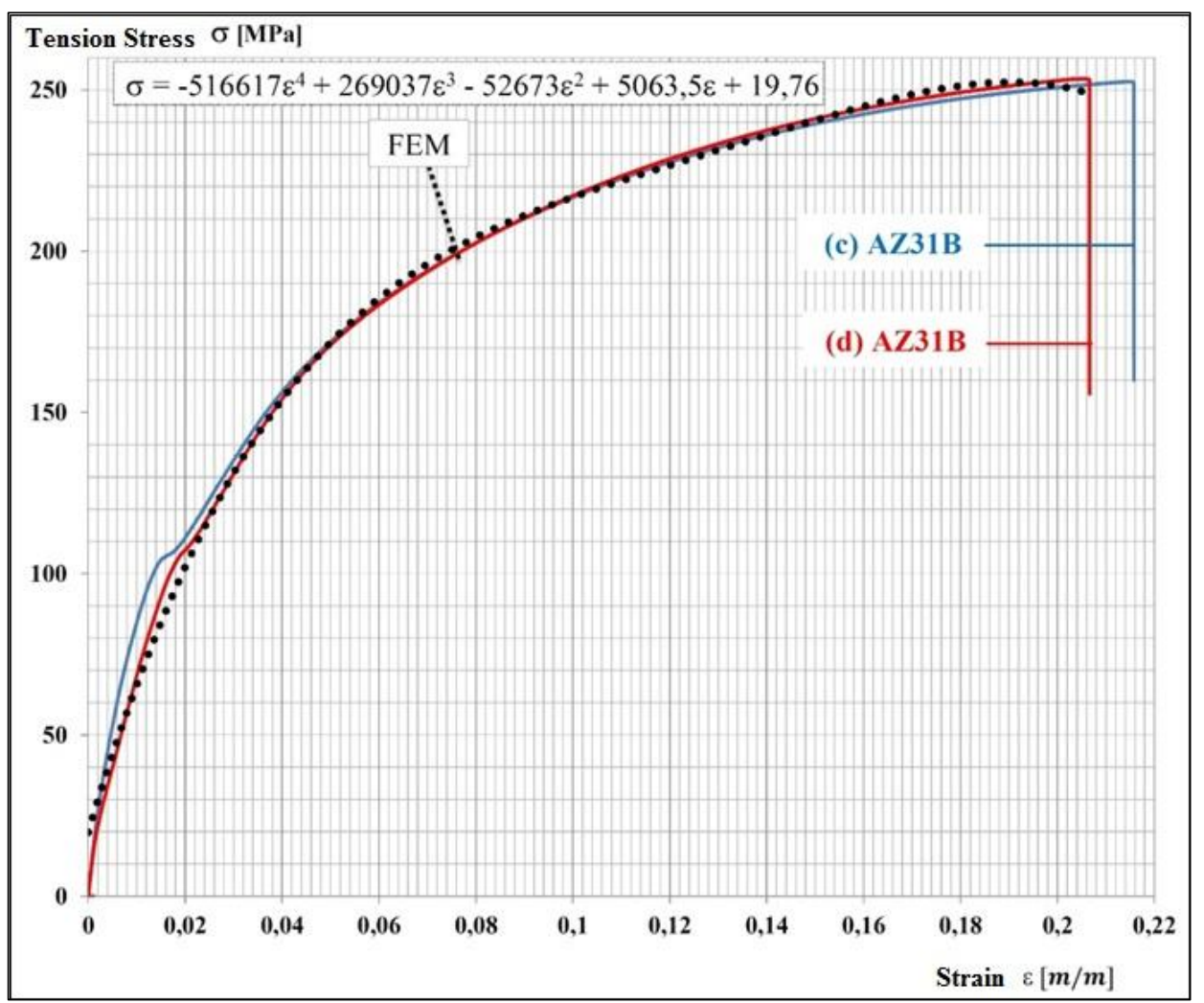

Figure 7. Tension test results of the Magnesium alloy AZ31B sheet with $1.5 \mathrm{~mm}$ thickness with a speed of $1 \mathrm{~mm} / \mathrm{min}$

The mechanical characteristics of the magnesium alloy AZ31B sheet with $1.5 \mathrm{~mm}$ thickness that were determined based on the tension test performed with a speed of $1 \mathrm{~mm} / \mathrm{min}$ are shown in Table 4. Since the materials which are having E modulus lower than $150.000 \mathrm{MPa}$ are investigated, tension test speeds were selected according to Table 3 in ISO 6892-1 which is $1 \mathrm{~mm} / \mathrm{min}$ respectively $18 \mathrm{MPa} / \mathrm{s}$.

Table 5. Mechanical characteristics of the Magnesium alloy AZ31B sheet with $1.5 \mathrm{~mm}$ thickness based on the tension test performed with a speed of $1 \mathrm{~mm} / \mathrm{min}$

\begin{tabular}{|c|c|c|c|}
\hline Sample/Material & $\begin{array}{c}\text { Tensile Stress } \\
(\mathrm{MPa})\end{array}$ & $\begin{array}{c}\text { Yield Stress } \\
(\mathrm{MPa})\end{array}$ & $\begin{array}{c}\text { Yield Rate A } \\
{[\%]}\end{array}$ \\
\hline (c) AZ31B & 252.6 & 156 & 21,8 \\
\hline (d) AZ31B & 253.5 & 146 & 21.0 \\
\hline AZ31B (Mean) & 253 & 151 & 21,4 \\
\hline
\end{tabular}

It is observed that the tests with respect to the main material characteristics satisfy the values specified in standard (ASTM 2010) as shown in Table 5. These details were given in FEM section.

\subsection{Analysis of Stress Mechanisms of the Sample Overlapped Joined with FSSW in the Tension-Shear Test}

\subsubsection{Analysis of Elastic-elastic Stress Mechanisms}

Elastic-elastic analysis is possible only when the tension-shear sample joined using overlapped FSSW (Figure 8) is subjected to stress values up to the linear elastic load value. When such a stress is present, two cylindrical stress sections (ød and ød1) shown in Figure 9 appear in the joining area. Based on a detailed examination of spot welding, Chao Y. J. created equations for elastic stresses. ${ }^{(16)}$ 


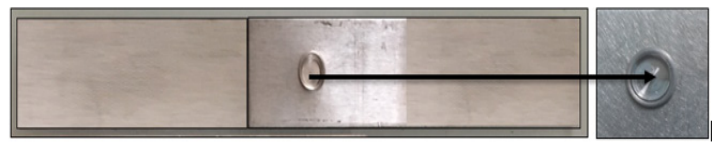

Figure 8. Upper view of the sample joined with overlapped FSSW

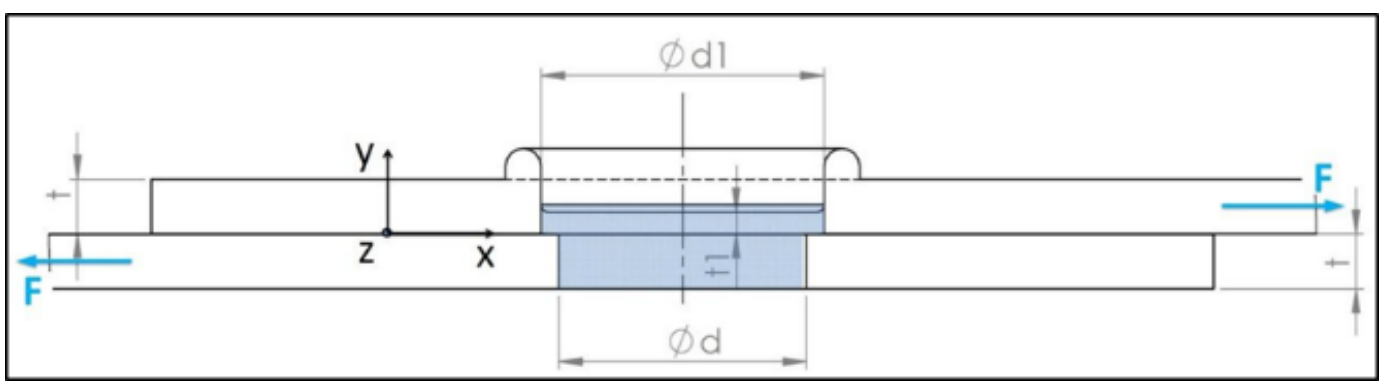

Figure 9. Geometric model and parameters of Tension-shear sample joined with overlapped FSSW

The elastic shear stress that occurs on the joint interface in the x-direction is shown in Figure 10.

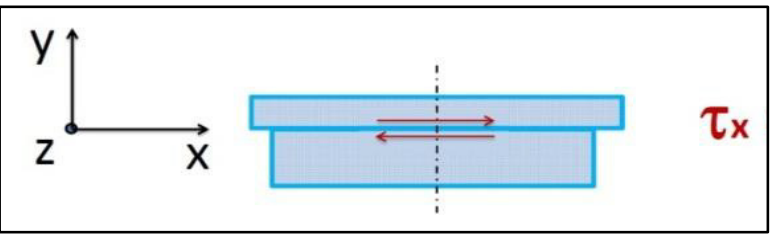

Figure 10. Elastic shear stress that occurs on the joint interface

The elastic shear stress on the $\mathrm{x}$ direction $\left(\tau_{x}\right)$ that occurs on the interface is calculated using equation $(1){ }^{(1,15)}$

$$
\tau_{x}=\frac{4 \cdot F_{y i e l d, \tau_{x}}}{\pi \cdot d^{2}} \leq \frac{f_{\text {yield }}}{\sqrt{3}},
$$

Where the yield shear force $\left(F_{\text {yield }, \tau_{x}}\right)$ in yield value $\left(f_{\text {yield }}=151 \mathrm{MPa}\right)$ obtained from the AZ31B main material test using Equation (1) is calculated as: $F_{y i e l d, \tau_{x}} \leq \frac{f_{y i e l d} \cdot \pi \cdot d^{2}}{4 \cdot \sqrt{3}}=\frac{151 \cdot \pi \cdot 7^{2}}{4 \cdot \sqrt{3}} N=3355 \mathrm{~N}$. Since the shear force in this yield stress is higher than the rupture value for the tension-shear tests, it is understood that this type of failure cannot occur. This failure type might only be observed if joint fusion does not happen or the diameter decreases from $7 \mathrm{~mm}$ to half this value, i.e. the joint is weak.

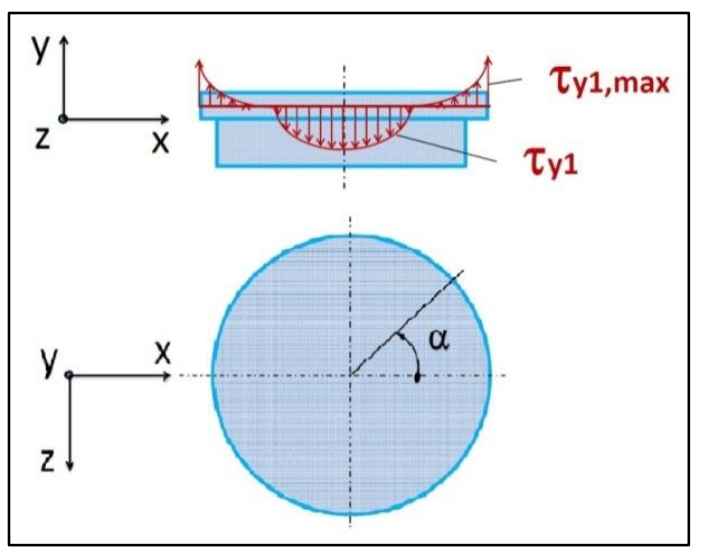

Figure 11. The occurrence of shear stress on the upper sheet in the y-direction

The shear stress that occurs on the upper sheet in the $\mathrm{y}$-direction (vertical to tension direction) has been determined as shown in Figure 11 [16].

The elastic shear stress that is vertical to the tension direction $\left(\tau_{y 1}(\alpha)\right)$ on the upper sheet (expressed with index 1) is calculated using equation (2). As observed in equation (2), the shear stress in the y-direction varies with $\cos 2 \alpha$ in the circumferential direction according to angle $(\alpha)$ and the maximum shear stress value in y direction $\left(\tau_{y 1, \max }\right)$ is calculated using equation (3) [15].

$$
\begin{gathered}
\tau_{y 1}(\alpha)=\tau_{y 1, \text { max }} \cdot \cos 2 \alpha \leq \frac{f_{y i e l d}}{\sqrt{3}} \\
\text { Here: } \tau_{y 1, \text { max }}=\frac{F_{y i e l d, \tau_{y 1, \text { max }}}}{t_{1} \cdot d_{1}} \leq \frac{f_{\text {yield }}}{\sqrt{3}}
\end{gathered}
$$

The shear force in the yield value $\left(f_{\text {yield }}=151 \mathrm{MPa}\right)$ obtained from the AZ31B main material test in Equation (3) can be calculated as:

$$
F_{y i e l d, \tau_{y 1, \max }} \leq \frac{f_{\text {yield }} \cdot t_{1} \cdot d_{1}}{\sqrt{3}}=\frac{151 \cdot 0.6 \cdot 8}{\sqrt{3}} \mathrm{~N}=558 \mathrm{~N} .
$$

Given that the value of this shear force in the y-direction $\left(F_{\text {yield, } \tau_{y 1, \text { max }}}\right)$ is close to the values measured in the tension-shear tests, this type of failure might occur.

The bending stress that occurs on the upper sheet in the 
y-direction (vertical to tension direction) is shown in Figure 12.

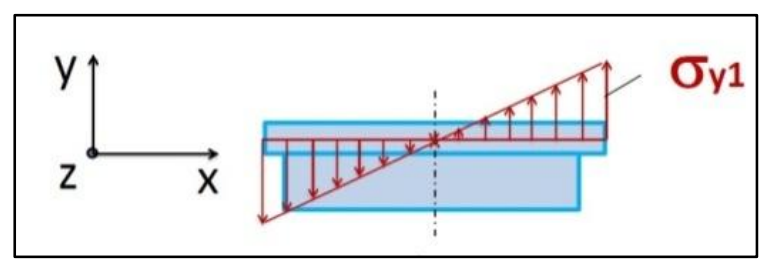

Figure 12. The bending stress vertical to the tension direction on the upper sheet

The elastic bending stress $\left(\sigma_{y 1}\right)$ caused by the secondary moment load vertical to the tension direction on the upper sheet is calculated using equation (4), derived from the static balance law of moments in the z-direction. As is seen in the equation (4), the bending stress in the y-direction varies with diameter according to the moment of inertia $\left(I_{1}\right)$ and is calculated using a maximum value $d_{1}[1,15]$.

$$
\begin{gathered}
\sigma_{y 1}=\frac{F_{\text {yield }, \sigma_{y 1}} \cdot\left(t_{1}+t\right) \cdot I_{1}}{d_{1}} \leq f_{\text {yield }} \\
\text { Here: } I_{1}=\frac{\pi \cdot d_{1}{ }^{4}}{64}
\end{gathered}
$$

The yield bending force $\left(F_{y i e l d, \sigma_{y 1}}\right)$ in the yield value $\left(F_{y}=151 \mathrm{MPa}\right)$ obtained for the AZ31B main material test in Equation (4 and 5) can be calculated as: $F_{y i e l d, \sigma_{y 1}} \leq$ $\frac{64 \cdot f_{\text {yield }}}{\left(t_{1}+t\right) \cdot \cdot d_{1}{ }^{3}}=\frac{64 \cdot 151}{(0.6+1.5) \cdot \cdot 8^{3}} N=2,86 N$. The very small yield force that is required to achieve yield stress in the material shows that the overlapped joint is not resilient to bending (secondary moment load) and bends readily. Therefore, an elastic-elastic calculation cannot be used to accurately determine the strength of the joint. An elastic-plastic or even a full-plastic calculation method is recommended in this case.

The tension-compression (bedding) stress that occurs on the upper sheet in the $\mathrm{x}$-direction (tension direction) is shown in Figure 13 [16].

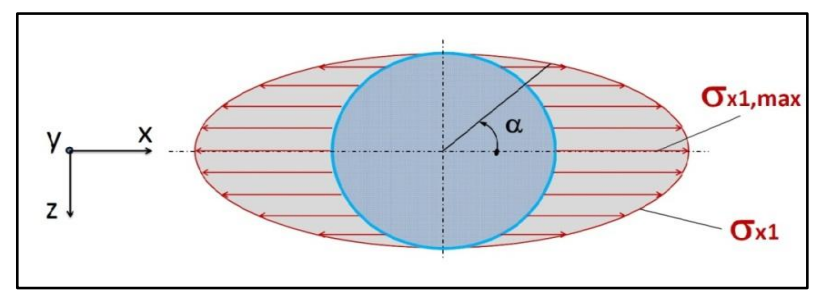

Figure 13. Shear stress that occurs on the upper sheet in the x-direction

The elastic shear stress $\left(\sigma_{x 1}(\alpha)\right)$ that occurs on the upper sheet in the tension direction is calculated using equation (6) and (9). In this equation, the tension-compression stress in the x-direction varies with $\cos$ in the circumferential direction according to angle $(\alpha)$ and the maximum value is calculated using equation (7) [16].

$$
\sigma_{x 1}(\alpha)=\sigma_{x 1, \max } \cdot \cos \alpha \leq f_{\text {yield }}
$$

$$
\text { Here: } \sigma_{x 1, \max }=\frac{4 \cdot F}{\pi \cdot t_{1} \cdot d_{1}} \leq f_{\text {yield }}
$$

The yield shear force $\left(F_{y i e l d, \sigma_{x 1, \max }}\right)$ in the yield value $\left(f_{\text {yield }}=151 \mathrm{MPa}\right)$ obtained using the AZ31B main material test for Equation (7) can be calculated as:

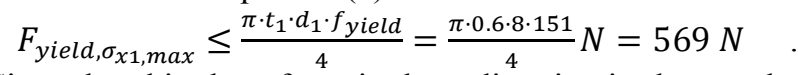

Given that this shear force in the y-direction is close to the values measured during the tension-shear tests, this type of failure might occur.

\subsubsection{Analysis of Elastic-plastic Stress Mechanisms}

The internal forces obtained by multiplying the stresses in joint cylinders with different stiffness values are shown in Figure 14. In elastic-elastic analysis, it is understood that local plastic deformation occurs quickly in Cylinder 1 (upper sheet) for very small tensile forces. Therefore, the normal stress in the $\mathrm{x}$-direction occurs assuming that a full-plastic deformation occurs at the $t_{1} \cdot d_{1}$ projection area, rather than according to the angle.

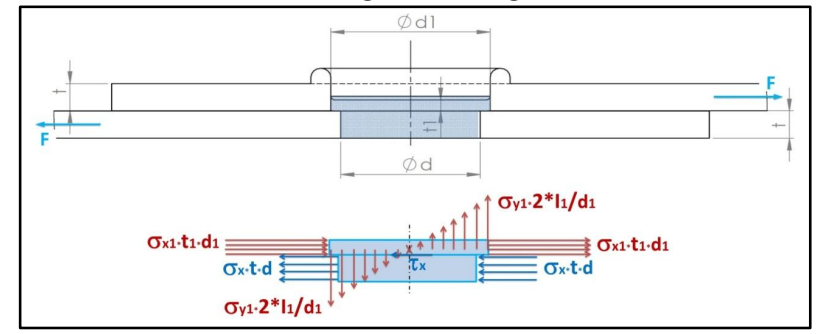

Figure 14. Static balance of full-plastic internal forces in joint cylinders.

When the static balance of forces in the tension direction is achieved using the equation $F_{x, i}=0$, the following equations are obtained:

$$
\begin{gathered}
2 \cdot \sigma_{x, 1} \cdot t_{1} \cdot d_{1}=2 \cdot \sigma_{x} \cdot t \cdot d \\
\sigma_{x, 1}=\sigma_{x} \cdot \frac{t \cdot d}{t_{1} \cdot d_{1}} \\
\sigma_{x, 1}=\frac{F}{2 \cdot t \cdot d} \cdot \frac{t \cdot d}{t_{1} \cdot d_{1}} \\
\sigma_{x, 1}=\frac{F}{2 \cdot t_{1} \cdot d_{1}} \geq \sigma_{y i e l d}
\end{gathered}
$$

When the static balance is achieved with the equation $M_{z, i}=0$, according to the midpoint of the shear interface of the moments, the following equations are obtained:

$$
\begin{gathered}
2 \cdot \sigma_{x} \cdot t \cdot d \cdot\left(\frac{t}{2}+\frac{t_{1}}{2}\right)=\sigma_{y 1} \cdot 2 \cdot \frac{I_{1}}{d_{1}} \\
\sigma_{x} \cdot t \cdot d \cdot\left(t+t_{1}\right)=\sigma_{y 1} \cdot 2 \cdot \frac{\frac{\pi}{64} d_{1}{ }^{4}}{d_{1}} \\
\frac{F}{2 \cdot t \cdot d} \cdot t \cdot d \cdot\left(t+t_{1}\right)=\sigma_{y 1} \cdot \frac{\pi}{32} d_{1}{ }^{3} \\
F \cdot\left(t+t_{1}\right)=\sigma_{y 1} \cdot \frac{2 \cdot \pi}{32} d_{1}{ }^{3} \\
\sigma_{y, 1}=\frac{16 \cdot F \cdot\left(t_{1}+t\right)}{\pi \cdot d_{1}{ }^{3}} \geq \sigma_{y i e l d}
\end{gathered}
$$

Equivalent stress: 


$$
\begin{gathered}
\sigma_{E Q, 1}=\sqrt{\left(\sigma_{x, 1}\right)^{2}+\left(\sigma_{y, 1}\right)^{2}}=\sqrt{\left(\frac{F}{2 \cdot t_{1} \cdot d_{1}}\right)^{2}+\left(\frac{16 \cdot F \cdot\left(t_{1}+t\right)}{\pi \cdot d_{1}{ }^{3}}\right)^{2}} \\
\sigma_{E Q, 1}=F \cdot \sqrt{\left(\frac{1}{2 \cdot t_{1} \cdot d_{1}}\right)^{2}+\left(\frac{16 \cdot\left(t_{1}+t\right)}{\pi \cdot d_{1}{ }^{3}}\right)^{2}} \geq \sigma_{\text {yield }} \\
F_{\text {ultimate }, 1}=\frac{\sigma_{\text {ultimate }}}{\sqrt{\left(\frac{1}{2 \cdot t_{1} \cdot d_{1}}\right)^{2}+\left(\frac{32 \cdot\left(t_{1}+t\right)}{\left.2 \cdot \pi \cdot d_{1}\right)^{3}}\right)^{2}}} \\
F_{\text {ultimate, } 1}=\frac{253}{\sqrt{\left(\frac{1}{2 \cdot 0.6 \cdot 8}\right)^{2}+\left(\frac{16 \cdot(0.6+1.5)}{\pi \cdot 8^{3}}\right)^{2}} N=2381 N} N \\
\text { In the joint interface }\left(d_{1}=d\right): \\
\sigma_{x}=\frac{F}{2 \cdot t_{1} \cdot d} \geq \sigma_{\text {yield }} \\
\sigma_{y}=\frac{16 \cdot F \cdot\left(t_{1}+t\right)}{\pi \cdot d^{3}} \geq \sigma_{\text {yield }} \\
\tau_{x}=\frac{4 \cdot F}{\pi \cdot d^{2}} \frac{f_{\text {yield }}}{\sqrt{3}}
\end{gathered}
$$

Equivalent stress:

$$
\begin{aligned}
& \sigma_{E Q}=\sqrt{\left(\sigma_{x}\right)^{2}+\left(\sigma_{y}\right)^{2}+3\left(\pi_{x}\right)^{2}}= \\
& \sqrt{\left(\frac{F}{2 \cdot t_{1} \cdot d}\right)^{2}+\left(\frac{16 \cdot F \cdot\left(t_{1}+t\right)}{\pi \cdot d^{3}}\right)^{2}+3 \cdot\left(\frac{4 \cdot F}{\pi \cdot d^{2}}\right)^{2}} \\
& \sigma_{E Q}=F \cdot \sqrt{\left(\frac{1}{2 \cdot t_{1} \cdot d}\right)^{2}+\left(\frac{16 \cdot\left(t_{1}+t\right)}{\pi \cdot d^{3}}\right)^{2}+3 \cdot\left(\frac{4}{\pi \cdot d^{2}}\right)^{2}} \geq \sigma_{\text {yield }} \\
& F_{\text {ultimate }}=\frac{\sigma_{\text {ultimate }}}{\sqrt{\left(\frac{1}{2 \cdot t_{1} \cdot d}\right)^{2}+\left(\frac{32 \cdot\left(t_{1}+t\right)}{2 \cdot \pi \cdot d^{3}}\right)^{2}+3 \cdot\left(\frac{4}{\pi \cdot d^{2}}\right)^{2}}} \\
& F_{\text {ultimate }}=\frac{253}{\sqrt{\left(\frac{1}{2 \cdot 0.6 \cdot 7}\right)^{2}+\left(\frac{16 \cdot(0.6+1.5)}{\pi \cdot 7^{3}}\right)^{2}+3 \cdot\left(\frac{4}{\pi \cdot 7^{2}}\right)^{2}}} N=1931 N
\end{aligned}
$$

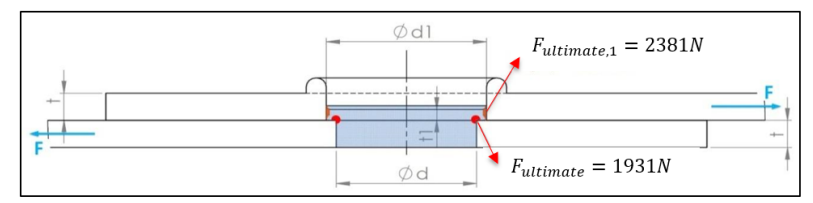

Figure 15. Minimum Tension-Shear-Force that is calculated analytically with the rupture stress of the material that causes rupture and its location

The minimum tension-shear-rupture-force $\left(F_{\text {min.,ultimate }}=1931 \mathrm{~N}\right)$ value that can be obtained in the tension-shear test using Equation (21b) and its location are presented in Figure 15. The calculated value was obtained using tension-shear tests with a maximum rupture force of $2000 \mathrm{~N}$ (Figure 23). The relative error rate is below 10\% and it can be concluded that the analytical stress mechanism model serves as a good verification. The fact that failure occurred on the joint interface diameter $(\varnothing \mathrm{d}=7$ $\mathrm{mm}$ ) and the upper sheet has been verified using the analytical stress mechanism model and tests.

\subsection{Review of Stress Mechanism of the Sample Overlapped Joined Using FSSW under Tensile-Shear Load via Numerically Modeling with FEM}

The geometric-static model prepared for the FEM of the tension-shear test sample is shown in Figure 16.

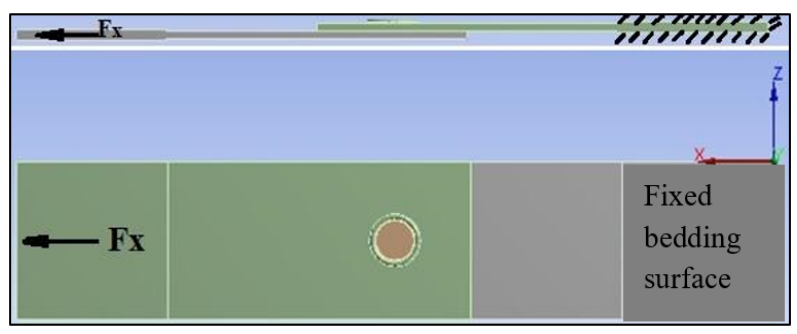

Figure 16. Static-geometric model of the tension-shear test sample

ANSYS simulation software is used for simulations. A FEM-Mesh model prepared for the FEM of the tension-shear test sample is shown in Figure 17. Solid 20171 elements and 77736 nodes were created. Minimum element size is selected as $0.25 \mathrm{~mm}$ around keyhole section. Fine mesh geometry was often used to obtain better results in the joint section and keyhole where the stress is high. Nonlinear ultimate stress analysis is performed by using non-linear material definition which is shown in Figure 7. Nonlinear material definition has been done by using stress-strain curve which is taken from test and used as input in non-linear analysis. The sample is fixed from one end and a tensile force $\left(F_{x}\right)$ is applied on the other end longitudinally (x-direction). $\mathrm{F}_{\mathrm{x}}$ is taken as $2000 \mathrm{~N}$ during simulation. The characteristics of the material, AZ31B, used in the FEM model are as follows:

Elastic Module $E=45000 \mathrm{MPa}$

Poisson Number $\gamma=0,35$

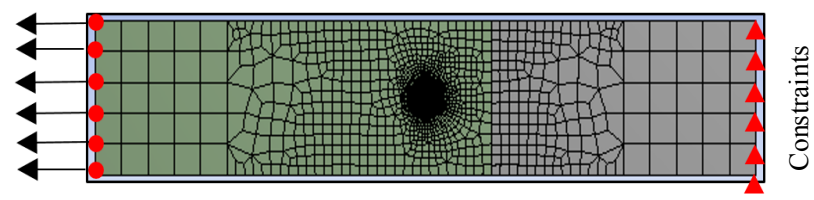

Figure 17. Finite elements model mesh of tension-test sample.

\section{Results}

Global deformation results obtained for the non-linear FEM-calculation of the tension-shear test of AZ31B sheets with $1.5 \mathrm{~mm}$ thickness that were joined using overlapped FSSW are shown in Figure 18 and Figure 19. Only elongation results in the $\mathrm{x}$-direction (tension direction) are shown in Figure 16. 


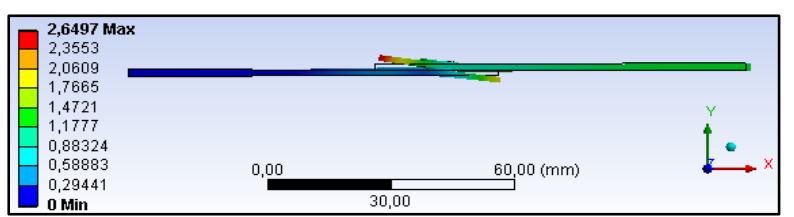

Figure 18. Global deformation [mm]

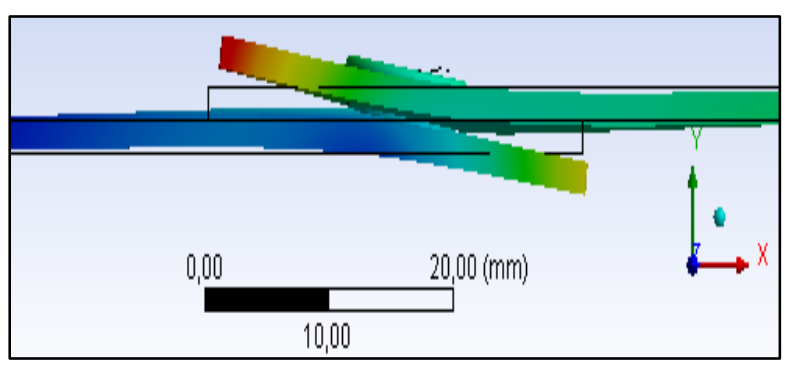

Figure 19. Detailed view of global deformation on the joint area

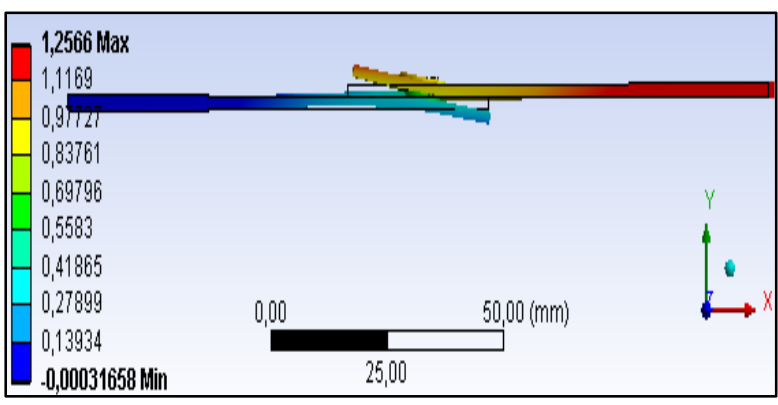

Figure 20. Elongation in tension direction (x-direction)

The Von MISES tensile stress that occurs as a result of the $2000 \mathrm{~N}$ maximum boundary load analysis is shown from the top view in Figure 21.

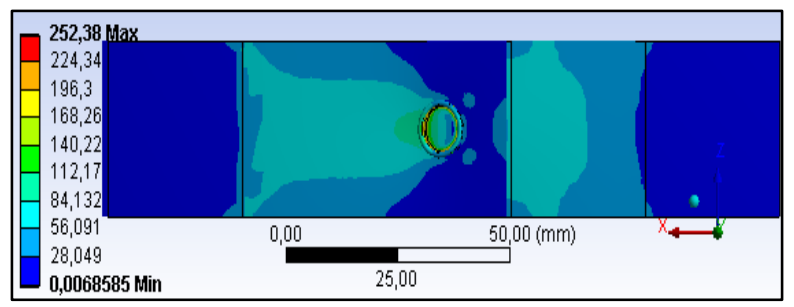

Figure 21. Von MISES tensile stress [MPa]

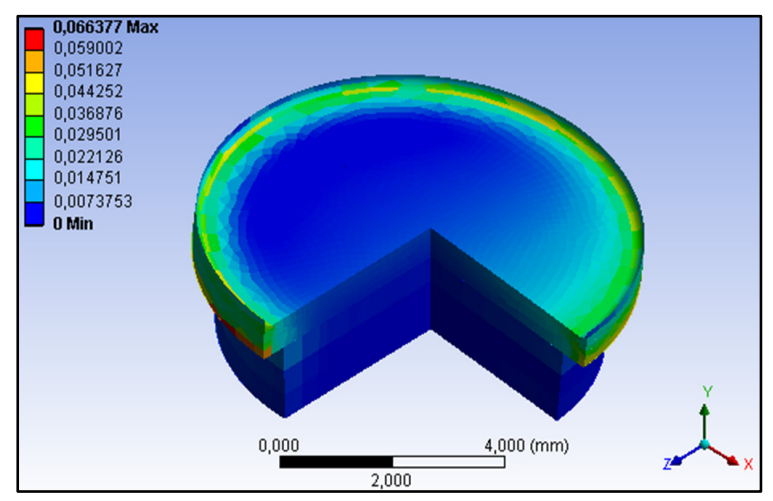

Figure 22. View of plastic strain obtained as a result of $1766 \mathrm{~N}$ tension force on the joint position
The plastic stress view obtained from the maximum boundary stress analysis shown in Figure 22 verifies that the stress area that was previously accepted in the equations used for the elastic-plastic analytical approach can be used in the calculation as $(\mathrm{d} \cdot \mathrm{t})$ and $(\mathrm{d} 1 \cdot \mathrm{t} 1)$ (Compare with Equation 8, 11, 16, 18 and 19).

A comparison graph of the FEM-Analysis result with the results of the tension-shear tests (for C1-C5 samples) after overlapped joining of the AZ31B Magnesium alloy sheets with $1.5 \mathrm{~mm}$ thickness using FSSW method is shown in Figure 19. C1-C5 samples FSSW experimental details are that stirring end immersion depth $(\mathrm{Hw})$ is $0,9 \mathrm{~mm}$, stirring rotating speed is $1800 \mathrm{rpm}$, immersion time (Tw) is $10 \mathrm{~s}$ and waiting time $(\mathrm{Te})$ is $15 \mathrm{~s}$. Despite $\mathrm{C} 1-\mathrm{C} 5$ samples are exposed totally same experimental procedure, tensile forces are different. It is assumed that the reason of the differences between samples tensile forces are due to welding process condition variations. Samples were fixed to the test machine manually during welding and it can cause response variation on the samples. The constant fixing torque would be applied to the each sample during welding. In the future studies, side fixing will be done with torque meter to prevent tensile force variations between samples. In that study, it is seen that $\mathrm{C} 2$ and $\mathrm{C} 4$ samples fixing to the machine seems proper thanks to appropriate fixing from sample sides and these samples is considered for the correlation of FEM model.

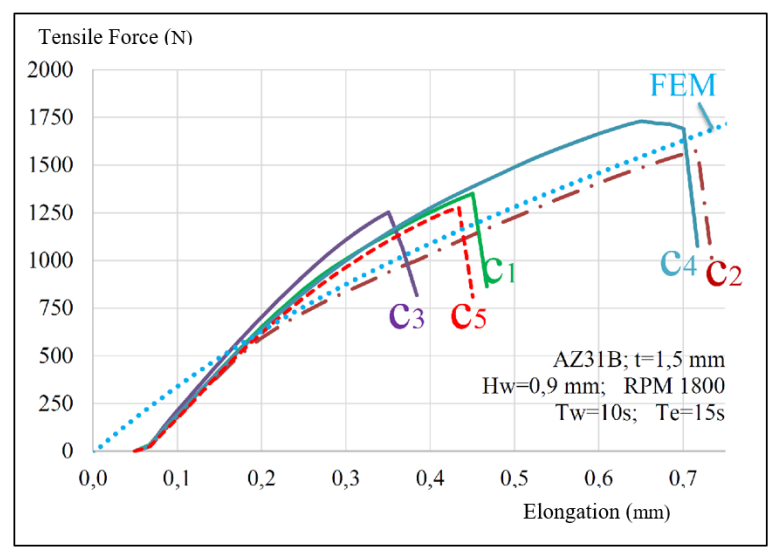

Figure 23. Comparison graph of FEM-Analysis result with the results of tension-shear tests (for C1-C5 samples) after overlapped joining of AZ31B Magnesium alloy sheets with $1.5 \mathrm{~mm}$ thickness using FSSW method (Here, t:thickness, Hw:stirring end immersion depth, RPM: revolution per minute of stirring end, Tw:immersion time in seconds (s) and Te:waiting time)

When the non-linear FEM Force-Elongation graph obtained from the analysis is compared with the result graphs for the tests shown in Figure 23, it is seen that the analysis result and test results are in good agreement. When the difference, which is nearly $150 \mathrm{~N}$, is compared with the maximum measured value $1750 \mathrm{~N}$, the maximum relative deviation is determined to be below $10 \%$. Furthermore, it is evident that the test results for the FEM-Line are within the deviation values (amplitude) in the graph. 


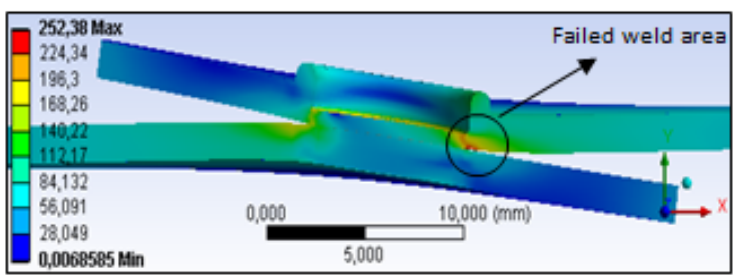

Figure 24. Detailed view of Von MISES comparative stress [MPa]

According to the detailed section view of the comparative stress on the joint area and below the ultimate boundary load, as shown in Figure 24 it is evident that it completely matches with the rupture stress results obtained experimentally and shown in Figure 24 and the low relative error rate was calculated below $10 \%$ when compared with the analytically calculated rupture force of $1931 \mathrm{~N}$. Figure 15 shows analytically calculated $F_{\text {ultimate }}$ point. That is compatible with the failure point which is shown in Figure 24. Also stress value from simulation which is $252,38 \mathrm{MPa}$ shown in Figure 24. Detailed view of Von MISES comparative stress $[\mathrm{MPa}]$ corresponds to the test results of AZ31 material tabulated in Table 5.

As a result, it is confirmed that the FEM-Analysis model was verified based on tests and analytical calculations.

\section{Conclusions}

Conclusions obtained from the study are as follows;

- Strain and force equations were developed by examining the analytical stress mechanism.

- Minimum rupture stress force was calculated and given that the relative error was below $10 \%$, a good verification was established for the analytical stress mechanism model.

- The occurrence of failure on the upper sheet starting from the joint interface diameter $(\varnothing \mathrm{d}=7 \mathrm{~mm})$ was verified by comparing the analytical stress mechanism model with tests.

- Non-linear FEM Force-elongation graph obtained as a result of FEM-Analysis was compared with the results of the tests. It was seen that the analysis and test results were in agreement. The difference was determined to be the maximum relative deviation that occurred below $10 \%$. Furthermore, it was seen that the test results of the FEM-Line were within the deviation values (amplitude) of the graph.

- It was evident that the comparative stress on the joint area and below the ultimate boundary load matches completely with the rupture stress obtained via tests, and a low relative error rate was calculated below $10 \%$ when compared with the analytically calculated rupture force.

- In summary, the equations derived from the FSSW-Tension-Shear-Test analytical review were verified using FEM-Analysis and tests. Using the developed analytical equations, it is possible to predict failure based on calculations without performing tension-shear tests.

As a summary, below points are understood clearly from the study;

(1) Formulas have been developed and made available for both elastic-elastic and elastic-plastic material strength conditions to make available the analytical stress analysis of point welded and single overlapped joints.

(2) The tensile-strain properties of the tensile test were empirically modelled and the tensile-shear test was confirmed by FEM modelling.

(3) Soft materials like here AZ31B Magnesium alloy have short elastic-elastic and long elastic-plastic area of tension material test. Therefore they have to be analysed with elastic-plastic strength condition. This should be taken into consideration especially in stress concentration and force transfer regions.

\section{REFERENCES}

[1] Matek W., Muhs D., Wittel H., Becker M., Jannasch D., 2000, Roloff/Matek Maschinenelemente, 14. Auflage, Vieweg Verlag, Germany, ISBN 978-3-322-96976-7.

[2] Liyanage T., Kilbourne J., Gerlich A. P., North T. H., 2017, Joint Formation in Dissimilar Al Alloy/steel and $\mathrm{Mg}$ alloy/steel Friction Stir Spot Welds, Science and Technology of Welding and Joining, homepage: http://ww w.tandfonline.com/loi/ystw20, ISSN: 1362-1718 (Print) 1743-2936 (Online)

[3] Shen Z., Gerlich A., 2018, Calculation of Welding Tool Pin for Friction Stir Welding of Thin Overlapping Sheets, International Journal of Advanced Manufacturing Technology, Springer online publication no 325651929.

[4] Bozkurt Y., Türker A., Salman S., 2018, The Investigation and Comparison of Friction Stir Spot Welding an Electrical Resistance Spot Welding of AA202 Aluminyum Alloy Joints, 4th International Conference on Engineering and Natural Science (ICENS), 2-6 May 2018, Kiev/Ukraine.

[5] Akdoğan A., Al ve alaşımları, 2008, homepage:http://www. yildiz.edu.tr/ akdogan/lessons/malzeme2/Aluminyum_ve_ Aluminyum_Alasimlari.pdf.

[6] Kim J., Yoon J. C., Kang B. S., 2007, Finite Element Analysis and Modelling of Structure with Bolted Joints, Elsevir Applied Mathematical Modelling 31, 895-911.

[7] Serindag H. T., Kiral B. G., 2016, Friction Stir Welding of AZ31 Magnesium Alloys-A Numerical and Experimental Study, Latin American Journal of Solids and Structures, http://dx.doi.org/10.1590/1679-78253162, (2016).

[8] Reynolds A.P., Tang W., Gnaupel-Herold T., Prask H., 2003, Structure, Properties, and Residual Stress of 304L Stainless Steel Friction Stir Welds, available online at www.science direct.com, doi:10.1016/S1359-6462(03)00024-1.

[9] Yuan W., 2008, Friction Stir Spot Welding of Aluminum 
Alloys, Missouri University of University of Science and Technologyhttp://scholarsmine.mst.edu/masters_theses/54 29.

[10] Li Y., Qin F., Liu C., Wu Z., 2017, A Review, Effect of Friction Stir Welding on Microstructure and Mechanical Properties of Magnesium Alloys, www.mdpi.com/journal/ metals, Metals 2017, 7, 524; doi: 10.3390/met7120524,1-1 4.

[11] Lai W. J., Feng Z., Santella M., Pan T. Y., 2013, Failure Mode and Fatigue Behavior of Ultrasonic Spot Welds with Adhesive in Lap-Shear Speciements of Magnesium and Steel Sheets, SAE Int. J. Mater. Manf. 6(2), doi: 10.4271/2013-01-1020, 1-7, (2013).

[12] Parra B., Saccon V. T., Guedes de Alcantara N., Rosendo T., Fernandes dos Santos J., 2011, An Investigation on Friction Spot Welding in AA6181-T4 Alloy, Tecnol. Metal. Mater. Miner., Sao Paulo, 8(3), 184-190.

[13] Ibrahim I. J., Yapici G. G., 2018, Application of a Novel Friction Stir Spot Welding Process on Dissimilar Aluminum Joints, Journal of Manufacturing Processes, https://doi.org/10.1016/j.jmapro.2018.08.018.

[14] Yang X. W., Fu T., Li W. Y., 2014, Friction Stir Spot Welding: A Review on Joint Macro and Microstructure, Property, and Process Modelling, Advances in Materials Science and Engineering, Hindawi Publishing Corporation http://dx.doi.org/10.1155/2014/697170.

[15] Niemann G., Winter H., Höhn B. R., Maschinenelemente Band 1: Konstruktion und Berechnung von Verbindungen, Lagern, Wellen, 4.Auflage, Springer Vieweg Berlin Heidelberg New York, ISBN 3-540-25125-1, 09-315.

[16] Chao Y. J., 2003, Ultimate Strength and Failure Mechanism of Resistance Spot Weld Subjected to Tensile, Shear or Combined Tensile/Shear Loads, Journal of Eng. Mat. and Techn., April 2003, 125, 125-132.

[17] Chao Y. J., Failure mode of Spot Welds, 2003, Interfacial Versus Pullout, Science and Technology of Welding and Joining 2003, 8(2), 133-137.

[18] Radakovic D. J., Tumuluru M., 2008, Predicting Resistance Spot Weld Failure Modes in Shear Tension Tests of Advanced High-Strength Automotive Steels, Welding Journal April 2008, 87, 96-105.

[19] Campanelli L. C., Suhuddin U. F. H., Antonialli A. Í. S., Santos J. F., Alcântara N. G., Bolfarini C., 2012, Metallurgy and Mechanical Performance of AZ31 Magnesium Alloy Friction Spot Welds, Elsevier Journal of Materials Processing Technology, http://dx.doi.org/10.1016/j.jmatpr otec.2012.11.002.

[20] Campanelli L. C., Antonialli A. Í. S., Alcântara N. G., Bolfarini C., Suhuddin U. F. H., Santos J. F., 2013, Lap Shear Test of a Magnesium Friction Spot Joint: Numeric Modelling, Tecnol. Metal. Mater. Miner., São Paulo, 10(2), 97-102, abr.-jun. 2013, http://dx.doi.org/10.4322/tmm.201 3.014 .

[21] EN 1993-1-1 Eurocode 3, 2004, Design of Steel Structures Part 1-1: General rules and rules for buildings, Ref. No. EN 1993-1-1 :2005: E.

[22] Owczarzak and Stracke, 2008, Eurocode 3 in Beispielen,
Seminarunterlagen,www.eurocode-seminar.de. 